\title{
Challenging Low Health Literacy in Rural Honduras: The Utilization of Charlas (Chats) for Patient-Centered Care
}

\author{
Linda Sookhoo
}

Published online: 4 July 2014

(C) Springer International Publishing 2014

\begin{abstract}
This study sought to qualitatively explore the use and need for health education information presented in a charla (Spanish for "health workshop") in two similar rural Honduran communities with low literacy levels. A Freirean approach was undertaken to explore adult health education based on cultural and patient experiences. Patients $(N=20)$ aged 18-65 were recruited to complete a charla evaluation survey in two mobile health clinics. Nine community health workers, four doctors, a charla presenter, nurse, and pharmacist were consulted for semi-structured interviews regarding health topics that affect the patients they serve. Data were analyzed using a combination of frequency counts for each item on the survey and content analysis. Findings show that $90 \%$ of patients understood that charlas are meant to improve health in their communities. At least $60 \%$ of patients were interested in learning about new topics including diabetes, hypertension, and feminine and dental hygiene. Participants believed more images and symbols would aid health information comprehension. Charlas convey health information in a manner easily understood by patients with low literacy levels because they utilize symbols and images. Health care providers noted cultural barriers, like machismo (macho) attitudes, can hinder comprehension of sexually transmitted diseases and use of contraception. In designing charlas, it is important to employ a culturally sensitive approach for patient-centered care. Future research should target increasing knowledge about how low health literacy can impact disease burden. Cohort studies should be conducted to explore the impact of charlas in disease prevention.
\end{abstract}

Keywords Health literacy · Charlas · Rural Honduras . Patient-centered care $\cdot$ Disease prevention

L. Sookhoo ( $₫)$

Stony Brook University, Stony Brook, NY, USA

e-mail: linda.sookhoo09@gmail.com
As global health challenges are increasingly addressed by nongovernmental organizations (NGOs), the understanding of how recipients of care with low literacy levels perceive change in the development process can provide a basis for better service delivery and community empowerment. Given this increase, most would believe that nongovernmental professionals are treating rural populations with a patientcentered and holistic understanding of how low health literacy levels can impact health outcomes. Unfortunately, that is not the case. Similar to the unchanged climate around education, poverty, and social inequality in a global context, transformative dialogues about disease and public health concerns have remained largely unaddressed. By comparison, PaascheOrlow et al. (2006) have argued that the implications of limited literacy levels should be understood as a challenge to the basic justice of a health care system structured for the most highly educated and powerful members of society.

The term "low literacy" is commonly defined as the ability to read, write, and comprehend information between the fifthand eighth-grade level of difficulty (Bastable 2011). At the same time, individuals with low literacy tend to have difficulty using commonly printed and written information to meet their everyday needs (Doak et al. 1996). For Honduras, rural populations rarely have higher than a sixth-grade education, and this poses a significant barrier to health care as it can hinder health information comprehension. The literacy rate for rural Honduras is $58 \%$ and the lowest for Central America (Jacobson 1997). Between a demand for medical care and a high volume of patients treated in mobile health clinics by NGOs, where routine medical care is sparse or nonexistent, health illiteracy often goes unrecognized and is rarely addressed. Schillinger et al. (2002) have defined health literacy as a culmination of the patients' capacity to read, perform basic math, understand prescriptions and labels, interpret blood sugar levels, and fulfill certain medical instructions. Not only does this skill set intertwine with the ability to comprehend and conceptualize disease frameworks, informed 
decisions, and how lifestyle impacts health long-term, but it also includes the capacity to understand basic health information and how to access services.

Health illiteracy is often interwoven with low education levels, but is also related to poor health and is widespread among minorities. Among disadvantaged populations, low health literacy contributes to a disproportionate burden of disease (Rosal et al. 2004). Recent statistics state that $74 \%$ of the poor and $86 \%$ of the extremely poor reside in rural areas of Honduras, consisting of mainly farmers, landless people, and laborers, with women and indigenous groups among the poorest (International Fund for Agricultural Development 2010). Health care in Honduras is officially accessed by only $60 \%$ of the population and largely limited and concentrated in urban centers (Johnson 2010). Such disparate access to health care casts the rural populace largely on the margins of society, leaving them vulnerable and their health needs basically neglected due to systematic and structural inequality.

While health illiteracy is a pervasive issue demanding the attention of health care professionals, patients often receive medical treatment without comprehensive and preventative health information. Rural regions are projected to experience this phenomenon on a grand scale. This can also result as a matter of different education levels among providers and patients, a lack of preventative health education for low literacy populations, or the inability of NGO health care workforces to effectively serve patients in impoverished communities. In recognition of the fact that patients are often disinclined to disclose their level of comprehension due to the temporary nature of services provided by NGOs, but also because of stigma, a patient-centered care approach calls attention to the ways in which providers working in a global context can be better prepared to serve patients with low literacy levels.

A patient-centered orientation for health care includes not only appropriate messages, collaborative goal-setting, and delivering post-visit reinforcements but also a redesign of the current care model, which mainly consists of periodic treatment (Paasche-Orlow et al. 2006). Rather, the current care model perpetuates nongovernmental services as "handouts" or placing "band-aids" on pressing health issues, without actually offering long-term change. Within the context of international development, it is unsustainable to simply provide medical care and medication in the absence of health education. Providing medical care with a patient-centered orientation should include the responsibility to provide preventative education in some form. Charlas offer a patient-centered platform to discuss public health needs that often go unmet.

Charlas (Spanish for "chats" or informal health workshops) can be used as a tool to dispense valuable and basic preventative health information to target communities with low literacy levels to improve health outcomes. A charla is organized like a flip-chart with different health topics for discussion after patients have been seen by medical personnel and is presented to every patient by a member of the organization or community health workers. In recognition of the usefulness of charlas in disease prevention, utilizing charlas in low literacy settings addresses a pressing need to cultivate a deeper understanding of personal disease risk and how environmental factors can place patients at risk for developing diseases.

This article reviews two community-based health interventions conducted in Honduras through Global Medical Brigades, a grassroots nongovernmental organization. The purpose of this study was to assess the preferences of rural Hondurans with low literacy levels for health education information received in mobile medical clinic charlas that ran for 3 days each in two similar communities. The secondary aim of the study was to examine if these preferences matched the previous health education implemented by the NGO. This study provides a brief overview of what health professionals treating the said demographic of patients deemed important to include in the charla. Data was compiled over the course of 6 weeks through charla participant surveys, literature reviews, and face to face interviews with medical professionals to better understand patient health problems. Ultimately, a new charla was created based on this data to promote health education with a culturally competent and patient-centered lens.

\section{Methods}

\section{Participants}

The study was approved by Global Medical Brigades. The communities of Alauca and Higuerito were selected from convenience sampling, as mobile health interventions were conducted during the time of data collection. Patients were derived from these rural communities because they have low literacy levels. Patients between the ages of 18 and 65 were eligible if they attended the charla portion of the mobile medical clinic and gave verbal assent. In-country staff made initial patient contacts by meeting with key community leaders prior to the mobile clinics being organized in their respective communities through outreach. In both communities, patients had limited health access. The patients had at least a sixth-grade education or less and demonstrated significant needs in terms of development (i.e., education and routine health care). These communities were predominantly agricultural characterized by homogeneity in terms of ethnicity, socioeconomic status, education systems, culture, and 
language. Analysis for the purpose of this study was a culmination of both patient and provider feedback.

Patients from both communities share significant characteristics. The main form of employment is agriculture on rented land, and the main products that are cultivated are coffee, corn, and beans. In Higuerito, there are really few work opportunities. Alauca and Higuerito are accessible by nonpaved roads, and Alauca is a relatively large and yet geographically isolated community. Even though there are at least ten different ethnic groups that reside in Honduras, the population in these communities are mestizos and speak Spanish, with elements of caliche. Caliche is jargon or informal linguistic styles often used by lower social classes in rural areas. Poverty is prevalent as shown in unmet basic needs in these communities. The educational system in both Alauca and Higuerito runs from kindergarten to sixth grade. The majority of homes are made of adobe, with an average household number of five people. El Higuerito does not have a health center in the community. The nearest health center is in Cedros, located about a 30 -min walking distance. There is no community health committee nor is dental care available in the community or at the health center in Cedros.

According to Red Solidaria and the World Food Programme in Honduras, the poverty line was determined to be L930 (US\$49.23) per person per month, and the extreme poverty line is L617 (US\$32.66) per person per month (as cited by Global Brigades Holistic Development 2011a, b). Additionally, Global Brigade explains that the average family income per month is estimated to be 1,500 Lempiras, which is approximately US\$15.87 per person for Alauca and 1,550 Lempiras per month, which is approximately US $\$ 16.41$ per person for Higuerito. These statistics place both communities beyond the extreme poverty line and show that both have similar levels of poverty.

In total, 35 people were interviewed during two medical interventions in Alauca and Higuerito. Twenty patients were surveyed altogether in two charlas, ten from each community, with a representative sample of ten males and ten females. Participants were over the age of 18 and randomly selected to fill out an evaluation survey. Participants were approached to complete the survey by Global Brigades staff at the conclusion of the charla presentation. Data collected from these surveys were used to generate themes for a new charla.

For the purpose of reviewing the proposed topics and to build a comprehensible charla for patients with low literacy rates, incorporating the ideas and feedback of providers in a cultural circle was important. Nine Guardianes de Salud, also known as community health workers (all female), from the communities of Zarzal and Zuzular (similar in demographic to Alauca and Higuerito) were asked their opinions regarding health topics affecting their communities. One Reyes de Irene (charla presenter), four doctors (two males; two females), one nurse, and one pharmacist all provided additional information regarding what they believed were health issues affecting rural communities, and this is summarized under "proposed topics" for the improved charla (Table 1 in the Appendix). All of these interviews were unstructured and used as background research to lay a foundation to address overarching problems with the current charla. These interviews also provided information about the cultural context of health within rural Honduras and the ways in which information should be appropriately conveyed in a culturally sensitive manner.

\section{Procedure}

Institutional Review Board approval was not obtained for this evaluation. However, "Protecting Human Research Participants" training through the National Institute of Health Office of Extramural Research was obtained prior to conducting the surveys. This training ensured that Global Brigades as an organization conducted ethical research involving human participants in qualitative interviewing with community members. The rights of participants were respected as no identifying information of the individuals were collected. This research was conducted for the benefit of others and communities at large. The health status of participants involved in this study was not utilized nor a screening factor. This research was conducted as part of improving the overall education received by patients based on their preferences for health education and as part of program evaluation to improve services provided by Global Brigades. Surveys were administered for the specific purpose of improving the quality of charlas and to make the education presented more comprehensible to patients, with the goal of increasing knowledge about disease risk and to contribute to generalizable knowledge about communities served in rural Honduras.

While working in rural Honduras in July 2012 under Global Brigades, research was conducted in mobile health clinics to improve a charla to integrate the perspectives of the patients being treated. After being seen by health care providers in the clinics, patients are required to attend a charla that covers a range of health topics including the maintenance of water, hand, oral, and personal hygiene, the proper use of latrines, and cervical and prostate cancer. For the purpose of this study, the Freire approach was utilized to review a health charla and to bridge the provider-patient health information disconnect due to disparate levels of health literacy. Research by Minkler and Cox (1980) summarizes the Freire approach in four steps: (1) residing with the people, (2) working in small groups to generate themes, (3) synthesizing the ideas of the people and presenting them as pictures and symbols, and (4) 
presenting the images through cultural circles with a coordinator.

Respondents were asked their opinions about the health topics currently presented (Table 1 in the Appendix), and an open-answer question format was used to compile patient preferences for new health topics in a revised charla. Charla presentation preferences were explored, including who patients preferred to present the charla within their communities. A cross-sectional design was employed, using qualitative research methods. Eligible patients were approached via random selection to participate in a brief evaluation survey after they received a charla conducted by a Global Brigades staff member.

The researchers were situated in the back or near the charla station of the brigade and introduced themselves. The rights of the patients were respected, and the purpose of the study was explained. The survey was in Spanish, and as with all aspects of the study, participants were informed that the survey was voluntary. Subjects were informed that they only had to answer questions they were willing to answer and could stop participating in the study at any point and that there were no risks or immediate benefits to them as a result of their participation in the study. As aforementioned, while working in a developing country and rural context, many participants had low levels of literacy which impeded the ability to obtain informed consent, so verbal assent was obtained instead. All of this information was provided in the language of the participants, being Spanish, and in-country interpreters were used when necessary due to low literacy rates.

Literacy was handled by designing a survey that was no more than two pages and could be completed by a person with at least a sixth-grade education. The survey was designed in this manner as the researcher had prior experience giving a charla and speaking and interacting with patients in similar rural communities. This was done with a general understanding about the level of literacy and what patients understood. This survey was reviewed by an in-country provider and tailored to meet the literacy level of the target subject pool. Understanding that the patients had low-literacy levels, providing in-country interpreters who work within the organization to be point persons for the patients was crucial, but seldom utilized, as many patients were able to follow basic instructions, like circling answers. Being that the subjects were directly exposed to the charla beforehand, conducting surveys within this context made data collection feasible and straightforward as the study was geared towards patient satisfaction with the health education they received.

Logistically, securing privacy was difficult to achieve because mobile health clinics are set up in a manner where entire schools are filled with lines outside of classrooms and in open spaces. However, all patients were apt to assenting to the survey. In regard to interviewing providers (community health workers, physicians, nurses, charla presenters, and pharmacists), a more formal setting was feasible as they were conducted in office settings, community health centers, discussion forums, or when reviewing the final proposed charla. While the survey was given exclusively to patients, consulting medical providers offered perspectives on what they considered to be prevailing health problems that should be included in the charla and cultural attitudes which affect health. These interviews were conducted in focus group settings to probe the ideas of the interviewees about charlas and how it can be improved to bridge illiteracy. This approach was also undertaken to extract overarching themes with an interdisciplinary focus.

\section{Measures}

The survey designed for this research included multi-option variables, as well as open-ended questions that would capture patient opinions about the charla. Subjects were asked to circle the items to indicate their answers in Spanish. Nominal values of "yes," "no," or "more or less" were used to assess whether patients liked the charla and if they believed charlas were improving health in their communities. Other questions included "What topics did you like that were mentioned in the charla?" and "What topics would you like to learn about?" These questions both had six to seven health education topics that the patients could provide feedback for by circling the topics they preferred. Two unstructured openended questions were included to illicit patient feedback around what topics they would like to learn about and how the charla can be formatted to make health information more easily understood, considering rates of illiteracy in rural contexts. Participants responded to open-ended questions by filling in their own comments such as writing "dental" for the question "What topics would you like to learn about?" and "more images" for the survey question "Do you have other ideas for us to improve the charla?" If at any point the subjects had questions regarding the interpretation of the survey, Global Brigade staff, who spoke the Honduran Spanish dialect proficiently in these communities, were utilized to clarify questions. After all 20 surveys were completed, participant responses about new health topic preferences were tallied.

NGO staff members were used as a general audience to review a prototype of the revised charla based on patient preferences. Information gathered through these general interviews provided a basis for cultural images they deemed appropriate for communicating health topics. For example, 
although family planning and sexually transmitted diseases were considered taboo topics, charla participants expressed interest in the subject matter, while the NGO staff provided feedback about the way such health topics should be presented in a charla setting. This method was incorporated to recognize cultural attitudes that shape the understanding of disease because creating a charla that effectively opens a conversation about public health issues in a comfortable space can help deconstruct the very systems that give rise to health illiteracy, while meeting the values of a population.

\section{Data Analysis}

Results were analyzed using survey responses out of the 20person sample. Data were coded independently by the author according to the number of responses circled for a single item in the survey. For example, if 14 out of the 20 survey participants answered they would like to see diabetes incorporated into the charla, then that response was recorded as 14/20 and then converted into a percentage (70\%). Through content analysis, key themes were organized according to NGO staff feedback and common themes expressed by community health workers. Opinions on the current charla and basic data related to presenting the charla to low-literate populations were incorporated in a final version of the charla. Greater emphasis was placed on the involvement and responses of the 20 patients in the sample to maintain a central focus on patient-centered care.

\section{Results}

Survey Results from Patients with Low Literacy Levels

Twenty patients completed the charla survey in Alauca and Higuerito in July of 2012. Ultimately, a new charla was created to cover chronic diseases, family planning, cancer, and sexually transmitted disease along with topics of the old charla, mainly because $90 \%$ of survey participants were satisfied with the old charla topics (Fig. 1). However, it is unknown as to why they reported such high satisfaction. Participants suggested using more images in the charla presentation. Thus, the charla was redesigned to incorporate more images so if patients did not comprehend the information being presented, they could conceptually translate images and symbols into health information.

Of the 20 patients, at least $60 \%$ reported they would like to see diabetes, hypertension, and exercise incorporated into the health workshop (Fig. 2), and also reported interest in topics like family planning and feminine and dental hygiene, which were not previously included in the charla. At least $50 \%$ of the respondents reported they would like to learn more about the benefits and consequences of water and soda and alcoholism. All participants agreed the charla was helping health in their community, but believed more images would aid comprehension. Findings show that $90 \%$ of patients understood that charlas are meant to improve the overall health of their communities and learned something, while $10 \%$ reported that they "more or less" learned something from the charla presentation.

Respondents were also asked their preferences regarding who should present the charla. These responses varied among the 20 participants, and some participants selected more than one answer. Forty-five percent of respondents believed that students (volunteers for the NGO) should present the charla, with the second most preferred being the NGO Reyes de Irenes (Global Brigades presenters) with $33 \%$. Only $12 \%$ of participants selected doctors to present the charla, and $10 \%$ of participants selected community health workers as their preference to hold the charla (Fig. 3).

In the case of two survey participants, friends and/or family were minimally and occasionally consulted regarding some questions, including items 6 and 9 on the survey ("Do you think the charla is for: a. education, $\mathrm{b}$. a requirement or $\mathrm{c}$. to improve the health of the community?" and "Do you have other ideas to improve the charla?"). Despite this fact, they all shared the same demographic background and also participated in the charla. This did not have a significant effect on the overall integrity of the data. This minimal level of collective participation only enhanced the research because it offered a holistic approach to what patients would like to learn about in charlas. This also depicted the social nature of the topics discussed in the charla, which often affects the entire household.

Interviews with Health Professionals of Higher Literacy Levels

In order to employ the Freire approach, health professionals working within the NGO were consulted to generate themes and garner feedback within cultural circles with a coordinator. Consulting with the female community health workers provided a female perspective on the health issues, as well as cultural norms that affect the health of women. The face to face interviews with medical professionals and community health workers revealed that family planning is a taboo topic in communities, as is birth control, using contraception, and other feminine hygiene issues. From a cultural standpoint, convincing males to use condoms is difficult for women due to machismo attitudes (macho attitude in Latino culture). A common theme that often surrounds sexually transmitted dis- 
eases within a rural context is suspicion of infidelity, especially if a woman approaches her husband about birth control use, despite recommendations by doctors. Research by Nuesch et al. (2001) has indicated that noncompliance is especially common when a patient has poor knowledge, understanding, and perception of a disease. This too, can be a result of machismo attitudes. Despite this setback, some physicians mentioned that it would be beneficial for the charla to include the fact that men can contract sexually transmitted diseases like syphilis, gonorrhea, and herpes by not using condoms. Similarly, family planning education can include birth control methods like birth control pills, intrauterine devices, and Depo-Provera birth control shot, all of which can be visually depicted in the revised charla.

Although machismo cultural attitudes can contribute to patient noncompliance and compromise health; health illiteracy, a lack of access, and poor resources can impede the ability of patients to lead a healthy lifestyle. For example, interviews with other medical professionals showed that a lack of access to insulin, glucometers and a healthy diet often contribute to the inability of patients to effectively manage chronic illnesses like diabetes and hypertension. Charlas can be used to inform patients that cervical and prostate cancer screenings are available in mobile health clinics and at local health centers. This way, opportunities to proactively participate in individual health can be increased.

Another theme that demonstrated structural inequality was a lack of potable water, which can contribute to gastrointestinal-related health issues, like parasites. For this reason, health topics of recognizing contaminated water and the purification of water were proposed to be included in the charla. A charla presenter commented that rural communities do not have large-scale sanitation systems like urban areas; therefore, maintaining structures built by NGOs, like latrines and water stations used to wash clothes and dishes, are crucial to public health. Although survey respondents rated lice and scabies treatment as their highest preferences for health topics to cover in the charla, a pharmacist recommended that such health issues can be addressed by maintaining personal hygiene and clean water in the prevention and control of these public health issues. Depicting sanitation methods and actionoriented images in charlas can effectively convey health information to even illiterate patients.

Between a lack of water and the abundance of access to soda and fruit juices sold in pulperías (small stores), dental hygiene was expressed as a primary concern. A nurse commented that there is no dental care available in either Alauca or Higuerito, and there is a significant prevalence of dental cavities. She recommended informing patients about using salt water if toothpaste is not available and flossing can be done by using a string or palm leave stem if dental floss is not available. This was a culturally appropriate message to include in the charla as rural communities do not readily have access to conventional methods of dental care.

Furthermore, charlas can simplify health information by using images and symbols that depict proper methods and incorrect methods of sanitation or health concepts represented by check marks and red " $x$ " marks (Fig. 4). The revised charla includes topics which incorporate images and basic knowledge about health to educate low-literate populations in the absence of routine medical care. For example, images of characters exercising and simply identifying foods to eat and foods to avoid through pictures serve to increase health knowledge. Purification methods depicted through images and measurements in charts communicate public health messages more easily for low-literate patients who may seldom have the ability to conceptualize and interpret measurements to purify water. However, implications of using charlas still need to be evaluated on a longitudinal scale and more indepth.

\section{Discussion}

Utilizing Charlas to Address Public Health Issues in Low-Literate Populations

Overall, the results indicate that there is a significant need and use for charlas in addressing public health issues in rural Honduras, where there are low literacy levels. Across both communities studied, patients reported positive attitudes about the current charla, but showed preferences for information about topics like family planning and chronic diseases. NGO professionals recognized a gap in the diseases for which they treated patients and the lack of health topics discussed in the previous charla. With regard to the charla presentation content, concepts of sexually transmitted diseases, family planning, dental care, diabetes, and hypertension informational needs have not been addressed. Patients recommended more images to improve the charla. These results reflect the need to present health information utilizing images, pictures, symbols, and visual aids, while incorporating the viewpoints of patients, to communicate health effectively to a low-literate populace, and it can be done through charlas.

Charlas can play a significant role in mobile health clinics to address public health issues. It is important to note that $80 \%$ of people in the world live in oral and visual cultures that learn through listening and watching rather than reading and writing (Goody 1968). Hence, charlas pose a viable medium to communicate health information from an approach that is culturally appropriate, but can also influence culture and undo myths about health. Charlas are also a preferred method of 
health education communication, rather than brochures, among Spanish-speaking Latinos, as they find the information more useful and have even experienced significantly greater increases in some areas of conceptual knowledge (Kaphingst et al. 2011). However, research by Peerson and Saunders (2009) recommends that health literacy should be compartmentalized to distinguish between the following: possessing information, understanding information, and the predisposition and capability to take action in response to information provided in health-promoting activities. Although charlas can prove beneficial to changing attitudes and improving health, if the structure of resource-poor communities remain deplorable, and health and gender inequality remains unchallenged, the ability to undo negative health behaviors can go unchanged. Utilizing an empowerment approach is essential to strengthen and build capacity within communities. This can be used to achieve greater health outcomes, while decreasing disease burden caused by health illiteracy.

From content analysis, the need to examine cultural attitudes of machismo and gender dynamics within a global context can serve to improve patient-centered care. In a research study about Honduran women's knowledge of family planning by Price and Asgary (2011), $89 \%$ of respondents were able to name at least one method of family planning, but $52 \%$ who wanted a birth control method were not utilizing one at the time. This research has shown that rural communities as a whole often have cultural taboos about discussing contraception and women are often reluctant to bring up sexually related issues. This can be due to a lack of concern with empowerment, which has been why literacy efforts on a wide-scale in a global context have failed, and similarly, health education concerning women and reproductive issues (Kickbusch 2001). By using a patient-centered care and an empowerment approach in community health interventions, women can increase control over their health and its determinants. In this way, charlas can potentially transform gender dynamics and increase health literacy.

Furthermore, as women represent a significant amount of patients seen in mobile health clinics, charlas are a better way to reach women as they prefer communication rather than written materials, especially in the absence of functional literacy. Research by Quinn et al. (2011) found that a majority of Latino women preferred to receive health information where it was discussed in a charla. Being that sexual education and family planning are taboo topics in Honduras, especially among rural areas, the charla provided a setting where both men and women can learn about sexual disease prevention in a medical context. Understanding how the social world affects illness is illustrated in how machismo cultural attitudes can limit and impede the use of contraception, influencing family planning as a result. To an extent, the charla can work to undo this system of gender inequality through education.

By comparison, findings in this study are highlighted as prevailing public health issues affecting rural populations in the literature and recent statistics. Research indicates that cervical cancer has the highest mortality rate for women affected by cancer in developing countries (Perkins et al. 2007); however, pap smears can be used to screen for cervical cancer. According to a study conducted in three rural health communities in Honduras, with a sample size of 134 participants, although $90 \%$ of participants heard about Pap smears, only $20 \%$ had one in the last year (Price and Asgary 2011). Statistics compiled by the Center of Health in Honduras (2009a, b) showed that hypertension was ranked as the leading cause of morbidity annually in Higuerito, with 613 cases in 2009, and the fourth leading cause of morbidity in Alauca, with 496 cases. Diabetes was ranked as the tenth leading cause of morbidity with 92 cases for Higuerito and 71 cases for Alauca (Centro de Salud Center of Health, Center of Health Statistics 2009a, b). Despite the fact that low health literacy contributes to a disproportionate burden of disease, charlas can be used to empower communities by raising health consciousness and to inform patients where they can obtain health screenings for chronic diseases.

Patient-centered care calls for greater involvement of patients in care and building systems of health around not only their preferences, but also the prevalence of disease within communities. By improving access to health information in charlas, heath literacy can be improved, but it is also essential to empower communities at the same time. The implications of a patient-centered care approach can aid overcoming structural barriers to health.

\section{Recommendations for Practice, Policy, and Research}

Barriers to health care fall in the category of a policy issue, and there is often a treatment gap in primary health care because of how little patients comprehend about their health conditions. Public policy decisions on health should focus on health promotion that is done "by" or "with" people rather than done "on" or "to" people (Nutbeam 2000). If achieving health literacy to improve health is a goal for NGOs, then addressing the root problem of inadequate education is also a real challenge. While providing comprehensible health education through charlas can improve health, decrease disease, and abate public health issues, macro-level challenges entail creating environments that support public health infrastructure, more equal allocation of resources, services, opportunities, and education to overcome health illiteracy in rural regions. Building sustainable 
projects involves working in a single location to build ongoing relationships to have a significant impact on community health (Suchdev et al. 2007). Therefore, NGOs with the aim to aid development in rural areas should adopt a holistic approach.

A holistic approach includes empowering rural populations in the areas of education and gender equality, while increasing choices and opportunities for sustainable living. Although poor health sits at the intersection of structural forces that contribute to poor socioeconomic status, poverty, and a lack of adequate access to health care, education as a means to empower society should be brought into focus to manage diseases and quality of life issues. In an effort to reduce social barriers within rural communities, promoting interdependence by educating community health workers, who are key community members, can play a pivotal role in improving the overall health of a population.

Minkler and Cox (1980) have suggested empowering community health workers by raising "health conscience" in their respective communities by encouraging dialogue about issues that include the lived experiences of Hondurans and how grassroots organizations contribute to change. Research by Suchdev et al. (2007) found that educating community health workers to teach health through charlas enables communities to play an integral role in the process of improving health and is part of the larger picture in public health work. Nongovernmental organizations can provide training to community health workers to promote preventative health education and increase health literacy.

A Freirean approach guided this research, and similarly, Freirean education, or rather popular education, can be used to address barriers to low literacy and health in rural communities. Popular in this case refers to the marginalized, disenfranchised classes and using education to create change by validating prior knowledge, connecting it with larger social realities, and inspiring collective action to change their reality (Wiggins 2011). If this education is associated with positive change in health-promoting behavior change - using community health workers can help raise health consciousness to affect widespread change. At the same time, people should actively participate in their health to contribute to the overall health of societies and facilitate social transformation. Being that charlas work to overcome health illiteracy to an extent, implementing charlas on a grand scale can contribute to greater collective organizing for policy change because it increases knowledge.

Researching the role of charlas in communities can be used to see if there is a reduction in disease prevalence through education. Many patients with chronic diseases do not have sustainable plans to manage health conditions because medication is indispensable and they lack community health care centers. For one community, the closest health care center was over 2 hours away. Often times there is no reliable transportation due to steep terrain, communities located on the mountains, and families do not have any money or economic means to fund a trip to the hospital. Although mobile health clinics can provide access to care for chronic patients, their medical supply has to continually be replenished and care remains transient. There is abundant need for rural community building, education to improve literacy, community empowerment, and organizing for change.

Improving education for women, workforce participation, and community involvement can also serve to strengthen health care in rural Honduras. On a worldwide scale, female political mobilization has increased the quality of life and health, including the expansion of family planning services that have allowed for better defense against contracting sexually transmitted diseases (Ehrhardt et al. 2009). Further research can be conducted to explore if including family planning and sexual health education in charlas has empowered women or changed cultural attitudes about contraception overtime.

Research by Raeburn et al. (2007) suggests that capacity building in the form of empowered, self-determined community action in collaboration with supportive governments and policies may be the greatest weapon at the disposal of health promotion. Although this may be true, many of the communities in rural Honduras are dispersed and have not been provided with community-organizing skills and tools to effectively make widespread change. Specific policies need to be put in place targeting health, poverty, education, and development in rural areas to strengthen health literacy. While community health workers have the ability to strengthen health in rural settings, very few communities have community health workers or organizations that can provide adequate and follow-up training. An increase in community health centers can increase health care and the ability of patients to monitor health; however, regular and reliable ways to navigate health care and maintain public health remain unseen. Even though providing charlas for health promotion is a model for working towards health literacy, the need for routine care, clinics, medical services, and educational access to improve literacy remains ubiquitous.

There are important limitations of this study. The applicability of these results to other settings and to broader populations is unclear. Still, more research is needed to assess the use of charlas with a wide-scale evaluation of public health education in various settings with representative samples. Reporting and assessment of the charla study was limited to working within one NGO. There was no prior evaluation to assess how much charla participants actually comprehended post-charla presentation, nor an assessment of how much 
information they retained. The time period was limited for this study, as was grant funding, and there was no assessment for behavior modification, if any, after implementing the newly revised charla. These proposed assessments should be longitudinally investigated for program evaluation.

Other limitations in this research are found in the survey. Although most participants were members of rural communities in Honduras, the study was restricted to a relatively small sample size. Surveying only two communities did not represent the 94 other communities served by this organization, much less communities not served altogether by the organization. Patients were confined to responses within a survey. Patients did not participate in open dialogue through focus groups to explore health and literacy, which could potentially draw greater perspectives on how illiteracy impacts health education and conceptual knowledge.

With the growing need to provide culturally appropriate and patient-centered care, research in the areas of quality assessment, patient satisfaction, and health information knowledge is necessary. Additional research is needed to identify specific attitudes about education and learning styles in low literacy contexts for effective interventions. Better understanding of public health issues can contribute to goal-oriented training for community health workers to leverage health within rural communities. Although the particular NGO used for this study previously implemented charlas on health interventions, more research is needed on NGOs that provide medical treatment without a public health education component and how they can implement sustainable strategies to serve regions with low health literacy levels.

Within population studies, it would be beneficial to look at the amount of women versus men who learn within the context of charlas, as a large portion of the literature looks at the perspectives of women learning from charlas. Although a significant amount of patients are seen in mobile medical clinics, men are usually underrepresented in the data, as they have work commitments, while women are traditionally responsible for the household and childcare. It is speculated that men can have higher disease risk as they are less likely to attend the charla and hence can have lower health outcomes. In addition, researchers should document characteristics of participants and interventions to better assess effective quality of life and disease interventions. Research is also needed to examine improvements in patient health literacy, but also how education and literacy can impact health.

Schools provide an effective platform for promoting, influencing, and reinforcing oral hygiene because children are most likely to be influenced in such settings during their early years. Although children were not included in the study, implementing charlas in school settings can teach children preventative health measures. Oral hygiene is particularly important as the school years are when children grow and develop long-lasting practices that influence lifestyle choices. By empowering children through health literacy, the burden of disease can potentially decrease and the overall health of future populations can theoretically improve.

While mobile health clinics can offer education that impact behavior changes, they can often leave without meeting local community needs due to illiteracy or a lack of comprehension. Furthermore, it is difficult to control for the lack of public structure, enabling factors and to measure behavior modification given time constraints and funding. An organization can provide the education and medication that patients need, but this does not imply greater health outcomes. Using medication correctly, monitoring blood pressure and glucose levels becomes complicated when there is a lack of individual blood glucose meters, blood pressure monitors, and professional personnel in rural areas to assist patients. Research has shown that self-management courses in community settings can serve to empower patients with chronic diseases in collaboration with health care professionals, but access to these services still needs to be developed (Wagner et al. 2005). Despite this setback, more research is needed to better understand how community health workers can bridge the gap in health illiteracy and be trained to challenge systems that leave marginalized populations underserved.

Comparative studies based around the prevalence of disease in relation to public health education workshops should be explored for evaluative purposes. The use of charlas to increase health literacy is still elusive as evaluation studies are needed with respect to changes in health behaviors and the impact on personal and public health practices. Further research is needed to determine other barriers to successfully using charlas to address public health issues such as unreached populations within a community and the total number of community members who actually have access to attending charlas.

Low levels of health literacy are a public health issue because they are a determinant of health. While patients communicated their preferences to see various health issues incorporated into a revised charla, the recommendation for visual aids and more images showed that patients did not fully comprehend health information being conveyed in the old charla. There were similarities in the topics research subjects chose to be included in the new charla and what health professionals recommended. Looking at health through a cultural humility lens enabled us to gather that diabetes, hypertension, family planning, and cancer are all illnesses interwoven with social factors. These similarities appear to be related to the ways in which rural populations in developing Honduras experience disease, how they are impacted by 
cultural attitudes, and how they utilize health care services. While education levels have remained stagnant for both communities, as a result, health literacy has also suffered. This indicated a larger call to action for public health education through patient-centered and culturally sensitive lenses.

Designing a new charla to address public health issues in this manner encompassed informed decision making tailored specifically to health education preferences to empower marginalized communities. The use of charlas to empower and educate rural Honduran patients can potentially lead to better health outcomes. Empowerment through preventative health information can decrease morbidity rates because patients are generally interested in learning about more chronic illnesses and preventative measures through verbal communication. Encouraging community members to participate in charlas and investing in public health infrastructure (i.e., community health centers) is a step in the right direction towards sustainability and holistic development.

While marginalized populations continue to experience the burden of balancing numerous injustices, empowering societies with preventative care and mobilizing members to serve in leadership roles can encourage greater accountability and sustainability. Illiteracy remains an issue to communicating health, but can be overcome through various methods, such as demonstrations and by using charlas. Health literacy includes a range of skills to take control of personal health and how it is influenced. Nonetheless, navigation skills and the ability to consider alternatives in lifestyle choices and to make informed decisions are all part of the development effort to increase overall societal health.

The health gap between urban and rural areas in developing countries alludes to the broader issue of health and structural inequality, which often leaves marginalized populations with an inability to respond to their illnesses. The welfare of rural Honduras is not simply dependent on giving them handouts or charity, because it will not eradicate the injustices they experience. Initiatives that empower rural populations to build stronger lives and encourage working towards sustainability can inspire organization for policy change and greater justice, but this should also involve widening their capability to take action to prevent and address illness.

Through empowerment and using the strengths perspective, partnering with community health workers and medical professionals helped to widen the scope of diseases affecting rural communities in a global context. Utilizing charlas as a means to address public health issues among low-literate populations is the beginning to bridging the gap between adverse health outcomes affected by illiteracy. At the policy level, attention should be given to education and training programs that facilitate improving health literacy and building capacity within communities. Although NGOs can play a fundamental role laying the groundwork for organizing developing communities, health literacy needs to become part of a larger agendum to increase education as a means to empower rural communities. As long as there is a health literacy gap, there will be health disparities. In order to decrease poverty and disparities in health care, policy changes at the country level that target a distribution of services to rural areas can prove effective in dismantling structural inequality which contributes to health illiteracy.

Acknowledgments The author acknowledges Global Medical Brigades for their full support and for kindly granting the permission to interview their patients. Funding for this research was generously provided for by the W. Burghardt Turner Fellowship Program. Special thanks and appreciation goes to Stony Brook University School of Social Welfare for their support.

\section{Appendix}

Table 1 Comparison of the original, proposed, and revised charla topics based on patient feedback

The revised charla contains elements of both the original and proposed charla as many patients expressed high satisfaction rates for the old charla and an interest in learning new topics

\begin{tabular}{lll}
\hline Original charla topics & Proposed topics & Revised charla topics \\
\hline Maintenance of water & Treatment of lice and scabies & Personal and oral hygiene \\
Hand, oral, and personal hygiene & Preventing hypertension & Recognizing contaminated water \\
Latrines & Exercise and diabetes & Purification of water \\
Cervical cancer & Alcoholism & Maintaining latrines \\
Prostate cancer & Water vs. soda & Cervical cancer \\
& Birth control & Prostate cancer \\
& Sexually transmitted diseases & Sexually transmitted diseases \\
& & Family planning \\
& & Diabetes \\
& & Hypertension \\
\hline
\end{tabular}


Fig. 1 Patient satisfaction with the original charla topics. This bar graph depicts a high level of patient satisfaction with the topics learned in the original charla

Fig. 2 Charla participant $(N=20)$ preferences for new health education topics (2012). Bar graph showing percent of patients who reported various health topics they would like to learn about in the charla

Fig. 3 Patient preference for charla presentation on Medical Brigades (2012). This graph depicts the specific groups of people patients preferred to present the charla to them on medical interventions
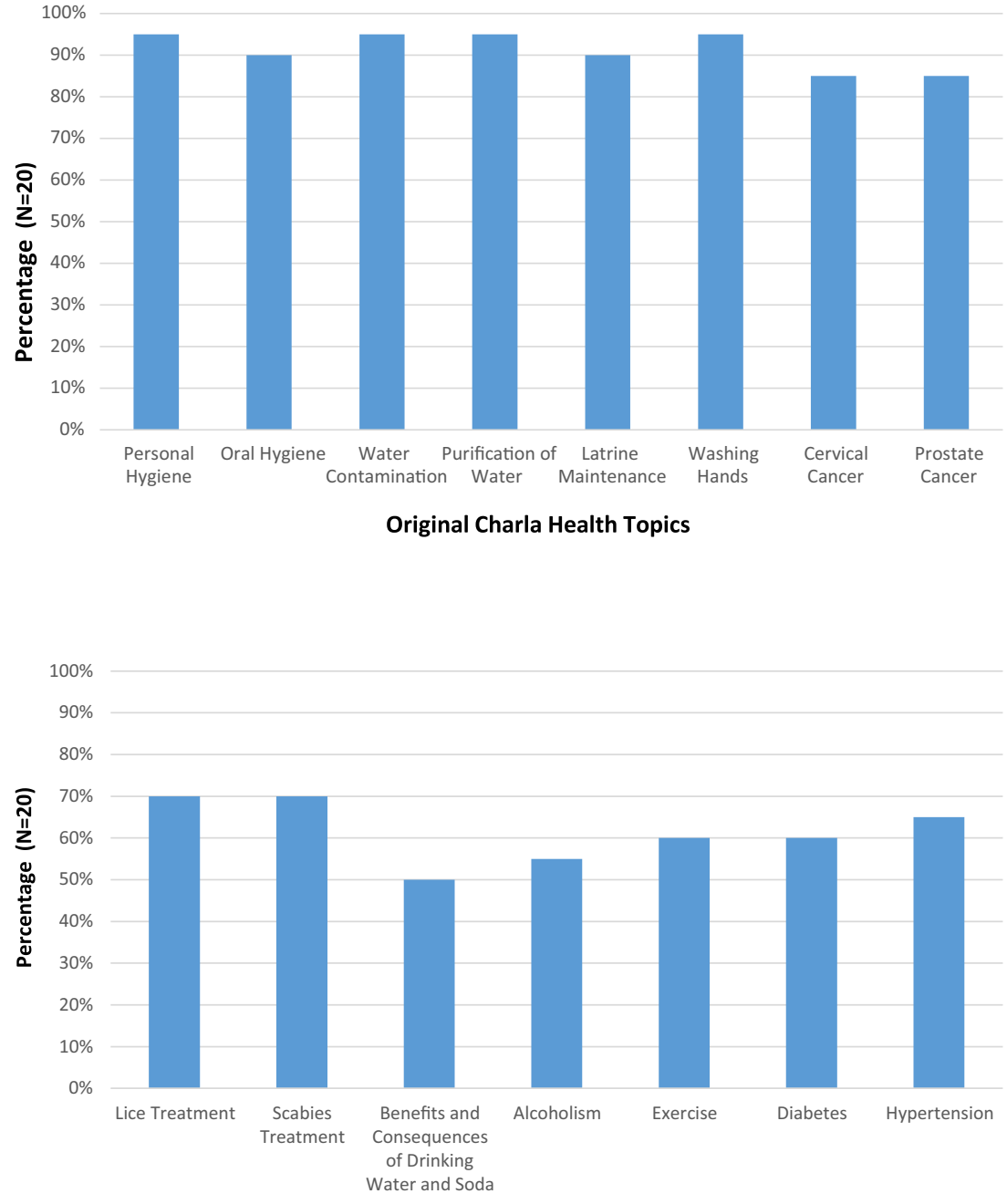

Proposed Health Topics

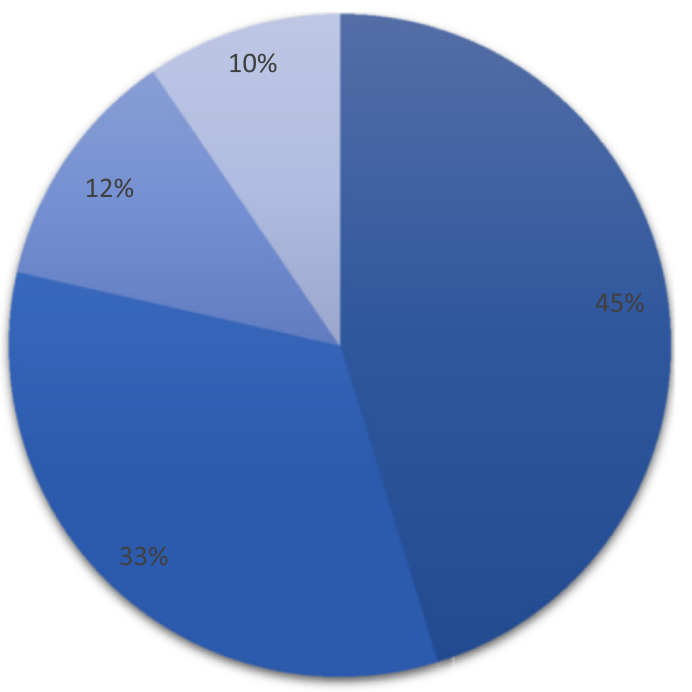

a Students $\quad$ Members of the Reyes Irene $\quad$ Doctors Community Health Workers 


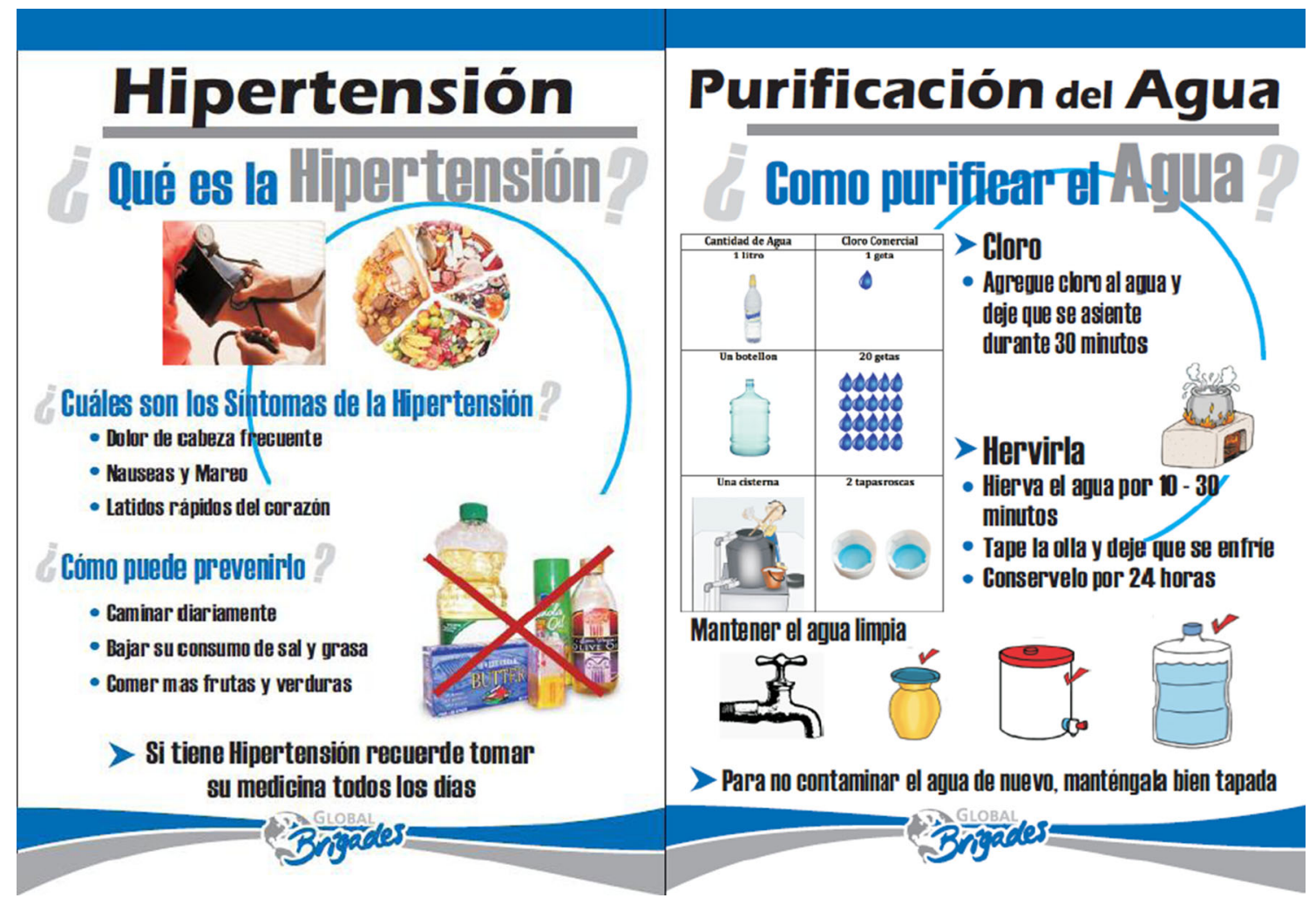

Fig. 4 Charla topics "Hypertension" (left) and "How to Purify Water" (right). This figure illustrates both health symptoms and prevention methods, with the majority of the presentation based in pictures and symbols, as recommended by Freire's approach

\section{References}

Bastable, S. B. (2011). Literacy in the adult client population. Sudberry: Jones and Bartlett Learning.

Centro de Salud (Center of Health) Statistics. (2009). Annual morbidities, 2009: CESAMO-Alauca.

Centro de Salud (Center of Health) Statistics. (2009). Annual morbidities, 2009: CESAMO-Higuerito.

Doak, C., Doak, L., \& Root, J. (1996). Teaching patients with low literacy skills (2nd ed.). Philadelphia: Lippincott.

Ehrhardt, A., Sawires, S., McGovern, T., et al. (2009). Gender, empowerment, and health: what is it? How does it work? Journal of Acquired Immune Deficiency Syndromes, 51, 1-18.

Global Brigades Holistic Development. (2011). Alauca, Honduras. Retrieved from http://www.globalbrigades.org/hondurascommunities-alauca.

Global Brigades Holistic Development. (2011). El Higuerito, Honduras. Retrieved from http://www.globalbrigades.org/hondurascommunities-el-higuerito.

Goody, J. (Ed.). (1968). Literacy in traditional societies. Cambridge: Cambridge University Press.

International Fund for Agricultural Development. (2010). Rural poverty in Honduras. Retrieved from http://www.ruralpovertyportal.org/ country/home/tags/honduras.

Jacobson, S. K. (1997). Rapid assessment for conservation education (RACE). Journal of Environmental Education, 28, $10-19$.

Johnson, C. (2010). Framing and the politics of public health: an examination of competing health narratives in Honduras. Global Public Health, 5, 1-14.
Kaphingst, K. A., Lachance, C. R., Gepp, A., et al. (2011). Educating underserved Latino communities about family health history using lay health advisors. Public Health Genomics, 14, 211-221.

Kickbusch, I. (2001). Health literacy: addressing the health and education divide. Health Promotion International, 16, 289-297.

Minkler, M., \& Cox, K. (1980). Creating critical consciousness in health: applications of Freire's philosophy and methods to the health care setting. International Journal of Health Services, 10, 311-322.

Nuesch, R., Schroeder, K., Dieterle, T., et al. (2001). Relation between insufficient response to antihypertensive treatment and poor compliance with treatment: a prospective case-control study. British Medical Journal, 21, 142-146.

Nutbeam, D. (2000). Health literacy as a public health goal: a challenge for contemporary health education and communication strategies into the 21st century. Health Promotion International, 15, 259-267.

Paasche-Orlow, M., Schillinger, D., Greene, S., et al. (2006). How health care systems can begin to address the challenge of limited literacy. Journal of General Internal Medicine, 21, 884-887.

Peerson, A., \& Saunders, M. (2009). Health literacy revisited: what do we mean and why does it matter? Health Promotion International, 24, 285-296.

Perkins, R., Langrish, S., Stern, L., et al. (2007). Comparison of visual inspection and Papanicolau (PAP) smears for cervical cancer screening in Honduras: should PAP smears be abandoned? Tropical Medicine and International Health, 12, 1018-1025.

Price, J., \& Asgary, R. (2011). Women's health disparities in Honduras: indicators and determinants. Journal of Women's Health, 20, 19311937.

Quinn, G., McIntyre, J., \& Vadaparampil, S. (2011). Preferences for hereditary breast and ovarian cancer information among Mexican, Cuban and Puerto Rican women at risk. Public Health Genomics, 14, 248-258. 
Raeburn, J., Akerman, M., Chuengsatiansup, K., et al. (2007). Community capacity building and health promotion in a globalized world. Health Promotion International, 21, 84-90.

Rosal, M. C., Goins, K. V., Carbone, E. T., et al. (2004). Views and preferences of low-literate Hispanics regarding diabetes education: results of formative research. Health Education and Behavior, 31, 388-405.

Schillinger, D., Grumbach, K., Piette, J., et al. (2002). Association of health literacy with diabetes outcomes. Journal of the American Medical Association, 288, 475-482.
Suchdev, P., Ahrens, K., Click, E., et al. (2007). A model for sustainable short-term international medical trips. Ambulatory Pediatrics, 7 , 317-320.

Wagner, E., Bennett, S., Austin, B., et al. (2005). Finding common ground: patient-centeredness and evidence based chronic illness care. Journal of Alternative and Complementary Medicine, 11, $7-15$.

Wiggins, N. (2011). Popular education for health promotion and community empowerment: a review of the literature. Health Promotion International, 27, 356-371. 